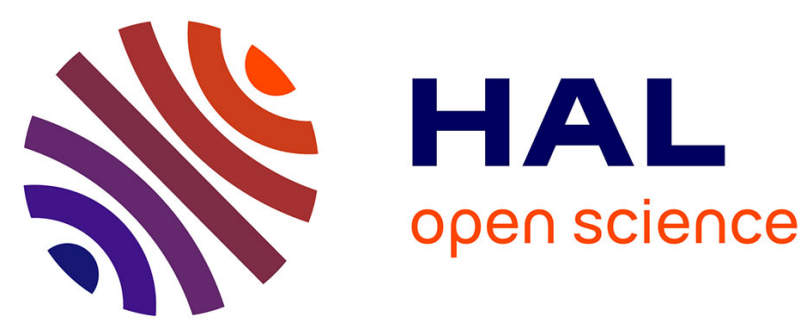

\title{
PULSED LASER TREATMENT OF Eu AND La IMPLANTED NICKEL : SURFACE ALLOYING, TRAPPING AND DAMAGE
}

G. Battaglin, A. Carnera, J. Chaumont, G. Della Mea, L.F. Donà Dalle Rose, A. Jain, Vainatey Kulkarni, P. Mazzoldi, A. Miotello, D. Sood

\section{To cite this version:}

G. Battaglin, A. Carnera, J. Chaumont, G. Della Mea, L.F. Donà Dalle Rose, et al.. PULSED LASER TREATMENT OF Eu AND La IMPLANTED NICKEL: SURFACE ALLOYING, TRAPPING AND DAMAGE. Journal de Physique Colloques, 1983, 44 (C5), pp.C5-481-C5-488. 10.1051/jphyscol:1983570 . jpa-00223155

\section{HAL Id: jpa-00223155 https://hal.science/jpa-00223155}

Submitted on 1 Jan 1983

HAL is a multi-disciplinary open access archive for the deposit and dissemination of scientific research documents, whether they are published or not. The documents may come from teaching and research institutions in France or abroad, or from public or private research centers.
L'archive ouverte pluridisciplinaire HAL, est destinée au dépôt et à la diffusion de documents scientifiques de niveau recherche, publiés ou non, émanant des établissements d'enseignement et de recherche français ou étrangers, des laboratoires publics ou privés. 


\title{
PULSED LASER TREATMENT OF Eu AND La IMPLANTED NICKEL : SURFACE ALLOYING, TRAPPING AND DAMAGE
}

\author{
G. Battaglin*, A. Carnera*, J. Chaumont**, G. Della Mea*, \\ L.F. Donà dalle Rose*, A.K. Jain***, V.N. Kulkarni*, P. Mazzoldi*, \\ A. Miotel $10^{+}$and D.K. Sood ${ }^{++}$ \\ * Istituto di Fisica dezl'Università, 35100 Padova, Itazy \\ * Laboratoire René Bemas, Université Paris XI, 91406 Onsay Cedex, France \\ ** Nuclear Physics Division, Bhabha Atomic Research Centre, Bombay 400085, \\ India \\ Istituto per Ia Ricerca Scientigica e Teenologica, 38050 Povo (Trento), \\ Ttazy \\ ${ }^{++}$RMIT, MeZbourne 3000, Australia
}

\begin{abstract}
Rẻsumé - L'irradiation par laser d'échantillons de Ni monocristallins implantés avec ions de La ou d'Eu produit une solution solide qui n'est pas de substitution, un changement du dommage de la matrice et un pic superficiel du dissous. Nous pré sentons une interprétation de ces résultats et une analyse des profiles de soluté dans le contexte de la diffusion dans une phase liquide.

Abstract - Laser irradiating of $\mathrm{Ni}$ single crystals implanted with La or Eu ions produces a non substitutional solid solution, a varying matrix damage and solute surface peaking. Explanation of these results and analysis of solute profiles in the context of a liquid phase diffusion model are presented.
\end{abstract}

\section{I - INTRODUCTION}

Survey of pulsed laser treatment (PLT) studies of metals $/ 1 /$ shows that the technique has been extensively used to produce metastable so lid solutions (MSS) at concentration well above equilibrium limits. According to the recently proposed general criteria /2/ the requirements for the formation of MSS by PLT are, miscibility for the components in liquid phase and good liquid phase epitaxy (LPE) with high cooling rates.

The previous PLT studies on $\mathrm{Ni}$ implanted with $\mathrm{Pd}, \mathrm{Sn} / 3 /, \mathrm{Ta}, \mathrm{Au} / 3,4 /$ and $H f / 5 /$ have all led to solid solutions in agreement with the above criteria. The Eu implanted $\mathrm{Ni}$ has shown a non substitutional solid solution after PLT $/ \sigma /$, where a substitutional solid solution would be expected $/ 2 /$. This result was explained in terms of enhanced defect trapping and defect-impurity interaction during LPE, caused by the large size difference between $\mathrm{Eu}(1.99 \AA \mathrm{\AA}$ radius $)$ and $\mathrm{Ni}(1.24 \AA \mathrm{A}$ radius $)$ atoms. In order to further confirm the influence of defect trapping on final phase formation we have done PIT of another similar system i.e. La implanted $\mathrm{Ni}$. 
The radius of $\mathrm{La}$ atoms $(1.87 \AA)$ is larger than $\mathrm{Ni}$ and further the $\mathrm{Ni}-\mathrm{La}$ phase diagram /7/ shows a negligible solid solubility in $\mathrm{Ni}$ but comple te miscibility in liquid phase. A non substitutional solid solution after PLT is observed in this case too. In addition we observe a large laser induced damage in $\mathrm{Ni}$ confirming the enhanced defect trapping and defect-impurity interaction. Another observed similarity concerns the peaking of la at surface in agreement with those reported for pulsed laser treated samples of $\mathrm{Eu}$ and $\mathrm{Hf}$ implanted $\mathrm{Ni}$. In this paper we present these results along with a comparison with those of $\mathrm{Ni}$ (Eu).

\section{II - EXPERIMENTAL}

Electropolished $\mathrm{Ni}$ single crystals (<100> orientation) having damage free surface and mirror like finish have been implanted with $300 \mathrm{keV}$ $\mathrm{Eu}^{+}$or $250 \mathrm{keV} \mathrm{La}{ }^{++}$ions to a dose of $1 \times 10^{16}$ atoms $/ \mathrm{cm}^{2}$. Pulsed ruby laser (20 or $16 \mathrm{~ns}$ FWHM) at energy densities up to $5.2 \mathrm{~J} / \mathrm{cm}^{2}$, was employed for carrying out irradiations in air on to several different regions of the implanted samples. In one case irradiation was perform ed in vacuum conditions $\left(\sim 10^{-2}\right.$ torr). From the spatially homogenised large spot of $15 \mathrm{~mm}$ size a region of $2.5 \mathrm{~mm}$ diamater was carefully se lected for irradiation which ensured an uniformity of $\pm 10 \%$ over the selected area. Samples were analyzed by Rutherford Backscattering (RBS) and channeling using a $1.8 \mathrm{MeV}{ }^{4} \mathrm{He}^{+}$beam. The backscattered particles were detected at $160^{\circ}$ using a surface barrier detector and the usual electronics with an overall resolution of $18 \mathrm{keV}$ FWHM corresponding to depth resolution of $180 \AA$ in $\mathrm{Ni}$.

\section{III - RESULTS AND DISCUSSION}

Fig. 1 shows the random and <100> channeling spectra for Eu/La implant ed $\mathrm{Ni}$ before and after laser treatment at the indicated energy densities. The channeling spectrum of Eu implanted $\mathrm{Ni}$ shows the surface damage peak, the characteristic 'knee' at a depth $x_{D}=245 \mathrm{~nm}$ and minimum yield $x_{\min }$ of $10.5 \%$, while that of La implanted $\mathrm{Ni}$ shows $\mathrm{X}_{\mathrm{D}}$ at $148 \mathrm{~nm}$ and $x_{\min }=33 \%$. The variation in the $x_{\text {min }}$ after laser treatment at the employed laser energy densities is plotted in Fig. 2 for both Ni(Eu) and Ni(La) systems.

An abrupt two fold increase in $x_{\min }$ at $.8 \mathrm{~J} / \mathrm{cm}^{2}$ is seen for $\mathrm{Ni}(\mathrm{Eu})$ (the corresponding dechanneling spectrum not shown in Fig. 1 , is found in Ref. /6/). Such an increasing has been correlated /6/ with the thre shold for melting of $\mathrm{Eu}$ implanted $\mathrm{Ni}$. At higher energy densities the $x_{\text {min }}$ reduces and becomes lower than its as implanted value while the 'knee' moves outwards always to the same depth of $40 \mathrm{~nm}$ (coinciding with the measured projected range, Rp for implanted Eu). On the other hand the regrowth behaviour of $\mathrm{Ni}(\mathrm{La})$ is very different under PLT. The $33 \% x_{\text {min }}$ of the implanted sample increases to $41 \%$ with higher and wider surface damage peak at $1.5 \mathrm{~J} / \mathrm{cm}^{2}$. The $x_{\min }$ and the damage peak width further increase with increasing energy density. A saturation effect in the minimum yield (Fig.2) is seen above $3 \mathrm{~J} / \mathrm{cm}^{2}$ where the aligned spectra become almost flat indicating formation of polycrystalline lay er /8/ or a deep and uniform damaged zone in Ni. As for the surface 


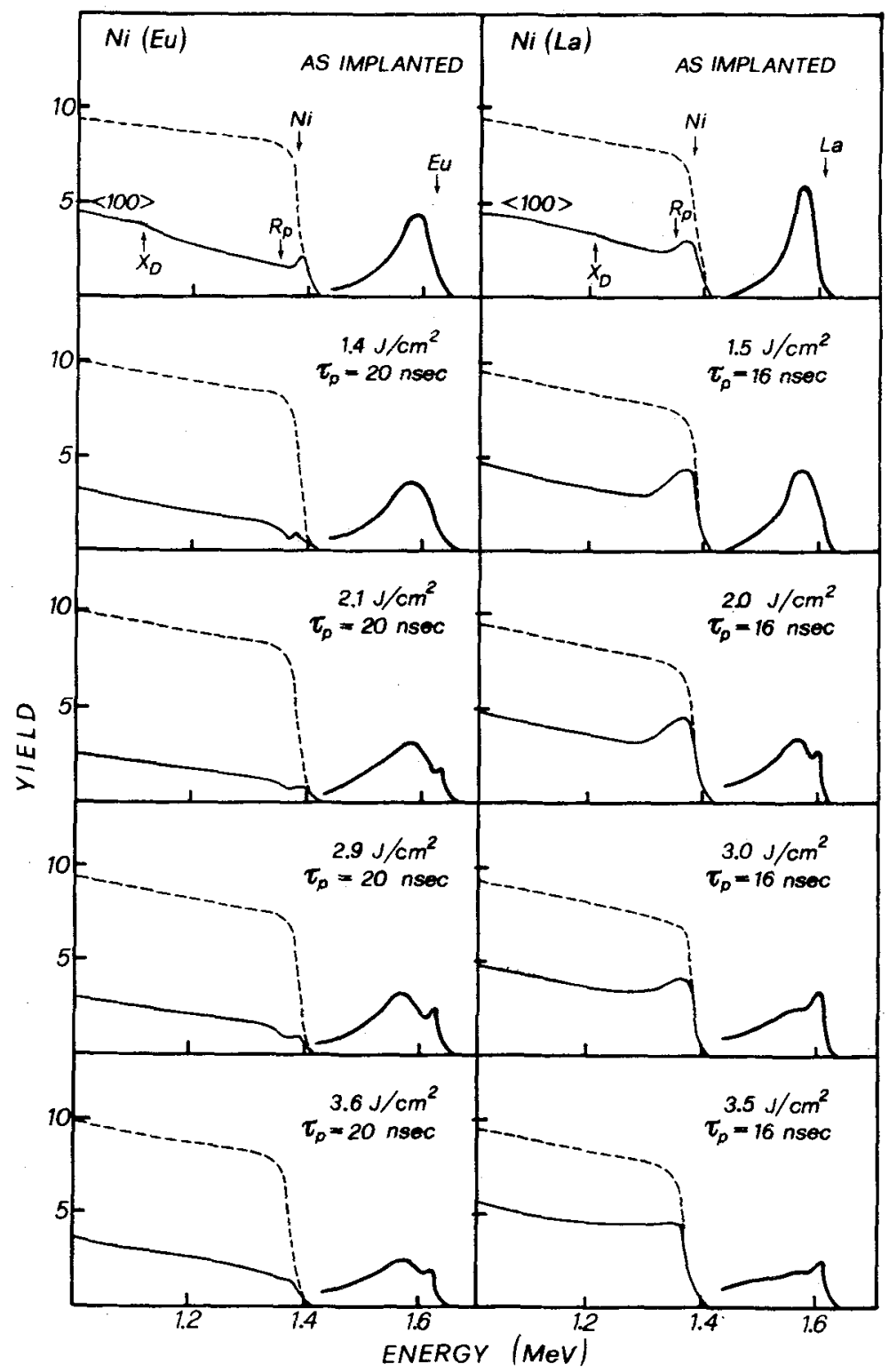

Fig. 1 - Random and $\langle 100\rangle$ channeling spectra of Eu/La implanted Ni before and after laser treatment. The spectra for $\mathrm{Eu}$ and La are magnified by a factor of ten. The random and channeling yields for both Eu and La overlap in all cases. 


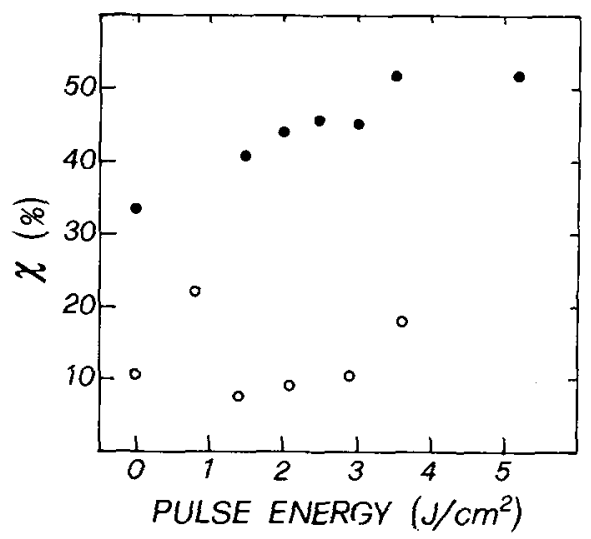

Fig. 2 - Dependance of minimum yield, $x$, on laser pulse energy for $\mathrm{Eu}(\mathrm{O})$ and La implanted (*) nickel.

alloy, the as implanted Eu and La form a nonsubstitutional solution in $\mathrm{Ni}$, as it may be seen by the overlap of their backscattexing yields in channeling and random directions. This is in agreement with the modifi ed Hume-rothery rules $/ 9 /$ which predict nonsubstitutionality for the implanted atoms having a radius $40 \%$ greater than the host one. On the other hand, for the reason mentioned in the beginning, PLT is expected to produce substitutional solid solution of $\mathrm{Ni}(\mathrm{Eu})$ and $\mathrm{Ni}(\mathrm{La})$. On the contrary, both systems form nonsubstitutional solid solution at the em ployed energy densities (Fig. 1). However, the broadening of the as im planted EU/La profiles after laser treatment confirm liquid phase diffusion of $\mathrm{Eu} / \mathrm{La}$ in $\mathrm{Ni}$. Another feature observed in the solute profiles of Fig. 1 is the appearance of a well defined and sharp surface peak at energy densities around $2 \mathrm{~J} / \mathrm{cm}^{2}$ and above. Similar solute surface peaking has been reported for $\mathrm{Ni}$ implanted with Hf after laser treatment in air.

The observed nonsubstitutionality of Eu/La after laser treatment and the $\mathrm{Ni}$ regrowth behaviour can be explained on the basis of defect trap ping during IPE. Channeling and TEM studies /3,6,10/ of laser treated pure Ni single crystals have shown the presence of quenched in defects.

From these reported results it becomes clear that the nature and amount of such defects depend on sample orientation laser energy density, pul se duration and other irradiation parameters. In other words we may say that defect trapoing depends on the thermal transients i.e. on tem perature gradients, melt depths cooling rates, resolidification veloci ties etc. in the pure $\mathrm{Ni}$ samples. For an implanted $\mathrm{Ni}$ sample, in addition, the defect trapping will depend on the type and concentration of implanted impurity atoms and on the defect-impurity interaction. It has been shown by positron annihilation studies in $\mathrm{Ni} / 11 /$ containing different impurities, that the impurity-defect interaction, more precisely the vacancy impurity binding energy, increases with the size of the impurity atom. Thus an impurity size dependance for defect trapping under PLI is expected. On this basis it can be thought that the relatively large sizes of $\mathrm{La}$ and $\mathrm{Eu}$ in comparison with $\mathrm{Ni}$ atoms enhance the defect trapping at the liquid solid interface and the simultaneously occurring solute trapping to such an extent that substitution 
ality is suppressed. As for the LPE of Ni under PLT the association of defects with impurity is seen by the clamped 'knee' at Rp for $\mathrm{Ni}$ (Eu) (Fig.1, also see /6/) and by the enhanced damage for Ni(La). However, if we remind that the $\mathrm{La}$ and $\mathrm{Eu}$ atoms have comparable size the question then arises about why, at increasing pulse energy densities Ni(La) shows an enhanced damage in opposition to $\mathrm{Ni}(\mathrm{Eu})$ behaviour. At first itmight appear that this discrepancy is correlated with the initial difference in the damage for the two systems. However this cannot be the case, since heat flow calculations for $\mathrm{Ni}$ (performed as for Al/12/) give melt depth extending beyond the respective damage depths $\left(\mathrm{X}_{\mathrm{D}}\right)$. This occurs at energy densities $\geqslant 1.4 \mathrm{~J} / \mathrm{cm}^{2}$ for both pulse durations and obviously damage memory cannot be retained in the liquid phase. Probably, the defect incorporation during LPE depends, apart from the size difference between impurity and host atoms, on some other factors (e.g. atomic configuration of impurity during trapping). In this regard it may be helpful to mention here that the regrowth behaviour under PLI of Ni(La) is influenced by the presence of implanted oxygen $\left(1 \times 10^{16}\right.$ atom $\left./ \mathrm{cm}\right)$ to the extent that a slight improvement in the Ni crystallinity is seen.

The possible mechanisms which can give rise to a solute surface peak after PLT are:i) segregation towards surface during resolidification, ii) incorporation in a surface oxide layer produced during PLT in air. A detailed discussion /13,14/ of segregation effects on the basis of melt front velocities suggests that these effects are inconceivable in case of PLT of metals. To experimentally decide about the solute incorporation in a surface oxide layer we have performed laser irradiation of $\mathrm{Ni}(\mathrm{La})$ in air and under vacuum $\left(10^{-2}\right.$ torr) conditions. The results are shown in Fig. 3. The surface peak which is seen under irradiation in air is almost absent under vacuum. If the peak were due to segrega tion it ought to appear in both cases. Its absence under vacuum conditions confirm the oxidation mechanism. As to probable surface oxidation we first observe that the heat of formation of $\mathrm{La}_{2} \mathrm{O}_{3} / 15$ / (and presumably for Eu oxide for which no data is available) is negative and outstandingly large in absolute value. This means that La (and Eu) oxidation is an energetically highly favoured process both in itself

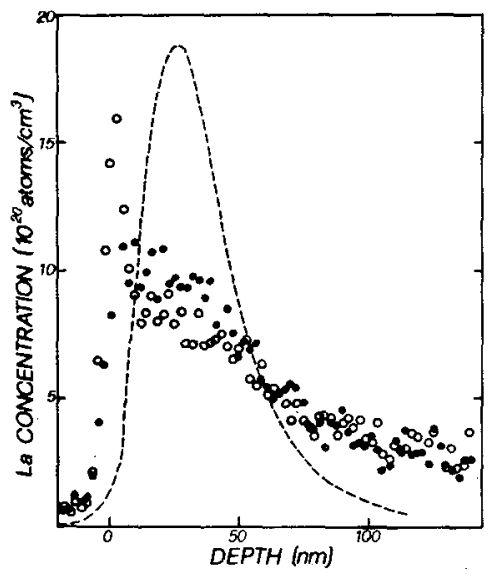

Fig. 3 - Depth concentration profiles of $\mathrm{La}$ in $\mathrm{Ni}$ obtained after laser irradiation ( $\tau_{p}=16 \mathrm{nsec}$ ) at $4.6 \mathrm{~J} / \mathrm{cm}^{2}$ in air (o) and in vacuum (•). The dashed line shows as implanted La distribution. 
and as compared with $\mathrm{Ni}$ oxide formation. As a consequence, a strong sur face oxidation may be expected for $\mathrm{La}$ and $\mathrm{Eu}$ as soon as they get at the $\mathrm{Ni}$ surface. An additional indication about oxygen role comes from a comparison between the two La profiles as obtained after PLT of La implanted $\mathrm{Ni}$ and La plus $\mathrm{O}$ implanted $\mathrm{Ni}$. It is observed that in the presence of implanted oxygen $\mathrm{La}$ is as a whole less mobile in the liquid matrix. This supports our view that oxygen acts as a trapping factor for La.

The experimental profile may be reproduced by integrating the impurity diffusion equation which keeps into account La/Eu capture at the liquid $\mathrm{Ni}$ surface due to oxidation processes. These calculations have been performed for the energy densities of $1.4,2.1$ and $2.9 \mathrm{~J} / \mathrm{cm}^{2}$ for $\mathrm{Ni}(\mathrm{Eu})$ and $1.5,2$ and $2.5 \mathrm{~J} / \mathrm{cm}^{2}$ for $\mathrm{Ni}(\mathrm{La})$. Similar calculations at higher energy densities are meaningless since the profiles are almost flat and the surface topography appears to be coarse when seen under scanning electron microscope. These features are now accepted as a si gnature of convective type effects in the molten metals /14,16/. The melt transients for the above mentioned energy densities are determin ed by heat flow calculations /12/. The reflectivity value of $R=.56$ was used for the samples /6/. For each energy density the impurity diffusion equation is integrated by a finite difference method and for a time equal to the molten phase duration. Surface capture is introduced by assuming that at each time step a small fraction $f$ of the La concentration in the first layer of the finite difference method is subtracted to the subsequent diffusion process. Thus the calculated La/Eu profile depends on the heat transient details and on two free pa rameters: the liquid diffusion coefficient $D$ and the effective capture parameter $f$. The calculated profile is finally convoluted using the ex perimental detector resolution and then compared with the experimental profile. Fig. 4 shows the calculated convoluted Eu/La profiles together with experimental ones. Through the fit procedure values for the effective capture parameter $f$ (which we assume to be the same in all cases for one system) and the diffusion coefficient $D$ are determined. The $D$ values are indicated in the figure and are consistent with the usual liquid phase diffusion coefficients /13,17/. For Eu the D value is found to be lower by a factor of three than that for La. As for the capture parameter $f$ we find its value to be the same for both $N i$ (Eu) and $\mathrm{Ni}$ (La) and equal to . $5 \%$. In view of the overall smaller surface peak of $\mathrm{Eu}$ when compared to the La case the fact that $f$ is the same for both may appear surprising, but this may be due to the slower Eu diffusion coefficient. As it may be noted, the La fit for $2.5 \mathrm{~J} / \mathrm{cm}^{2}$ does not reproduce the surface peak completely. In this case, however, $\mathrm{Ni}$ evaporation may become important as shown by heat flow calculations. By inclusing a small $\mathrm{Ni}$ evaporation in the calculations the improved fitting shown by dashed line in Fig. 4 a is obtained. An alternative explanation for the discrepancy may lie in an increased la surface capture at higher temperatures. 


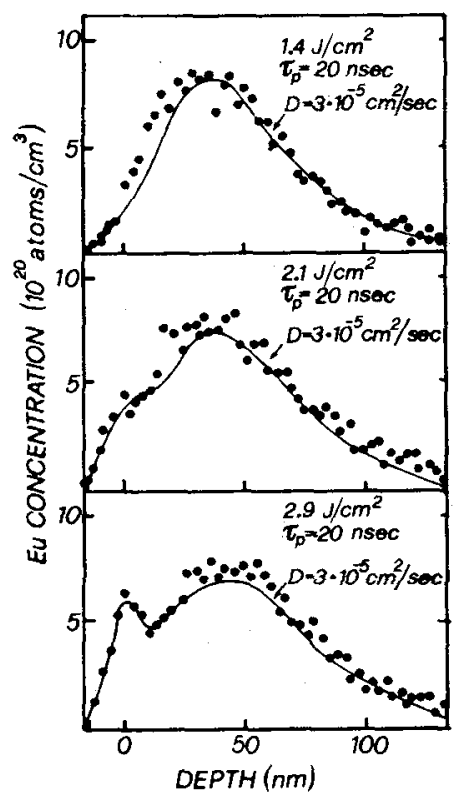

(a)

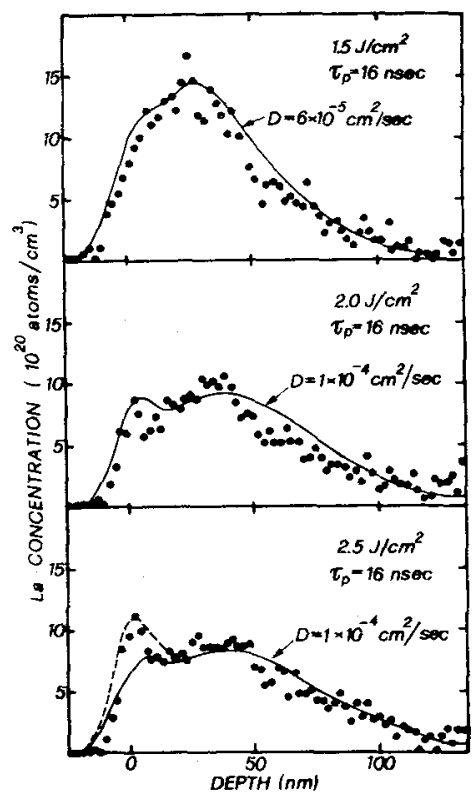

(b)

Fig. 4 - Depth profiles of a) Eu and b) La at the indicated energy den sities. Full curves show the best fit to observed depth profiles, obtained from liquid phase diffusion calculations using indicated diffusion coefficients and a surface capture parameter $f=0.5 \%$ (see main text). In $b)$ the additional dashed curve for $2.5 \mathrm{~J} / \mathrm{cm}^{2}$ refers to a calculation which includes also a small $\mathrm{Ni}$ evaporation.

\section{IV - CONCLUSIONS}

A substitutional solid solution of Eu/La in $\mathrm{Ni}$ could not be obtained by PLT of Eu/La implanted $\mathrm{Ni}$ single crystals: this fact is understood on the basis of enhanced defect trapping during the resolidification process. Completely different $\mathrm{Ni}$ regrowth behaviours are observed under PLT of the La and Eu implanted samples. The Eu/La surface peak is attributed to a mechanism of solute oxidation and trapping at surface. The liquid phase diffusion calculations including such a trapping mecha nism can satisfactorily explain the solute profiles.

\section{ACKNOWLEDGEMENTS}

We thank Mr. A. Rampazzo of the Sezione I.N.F.N. of Padova, for the drawings.

One of us (V.N.K.) will like to thank the International centre for Theoretical Physics (Trieste) for financial support in the form of a fellowship.

This work has been financially supported by the Piano Finalizzato Metallurgia of C.N.R. 


\section{REFERENCES}

11/ SOOD D.K., Rad. Eff. 63 (1982) 141.

/2/ SOOD D.K., Rad. Eff. Lett. 67 (1981) 13.

/3/ BUENE L., JACOBSON D.C., NAKAHARA S., POATE J.M., DRAPER C.W. and HIRVONEN J.K., in "Laser and Electron-Beam Solid Interactions and Materials Processing", edit. by J.F. Gibbons, L.D. Hess and T.W. Sigmon, p.583, North Holland, New York (1981).

/4/ BUENE L., POATE J.M., JACOBSON D.C., DRAPER C.W. and HIRVONEN J.K., App1. Phys. Lett. 37 (1980) 385.

15/ BUENE L., KAUFMANN E.N., MCDONALD M.L., KOTHAUS K., VIANDEN R., FREITAG $K$, and DRAPER C.W., in "Nuclear and Electron Resonance Spectroscopies Applied to Materials Science", edit. by E.N.Kaufmann and G.K. Shenoy, p.391, Elsevier North Holland, New York (1981).

16/ BATTAGLIN G., CARNERA A., DELLA MEA G., MAZZOLDi P., JAIN A.K., KULKARNI V.N. and SOOD D.K., in "Metastable Materials Formation by Ion Implantation", edit. by S.T. Picraux and W.J. Choyke, p. 333, North Holland, New York (1982).

17) HANSEN M., "Constitution of Binary Alloys", p. 887, McGraw-Hill, New York (1958).

/8/ CHU W.K., MAYER J.W. and NICOLET M.A., "Backscattering spectrometry", p. 251, Academic, New York (1978).

19/ SOOD D.K., Phys. Lett. A68 (1978) 469.

/10/ NARAYAN J. in "Laser and Electron-Beam Interactions with Solids", edit. by B.R. Appleton and G.K. Celler, P. 389, North Holland, New York (1982).

/11/ DLUBEK G., BRÜMER O. and MEYEN DORF N., solid state Commun. 27 (1978) 1219.

112/ DONA' DALLE ROSE L.F. and MIOTELLO A., Rad. Eff. 53 (1980) 19.

113/ MAZZOLDI P., DONA' DALLE ROSE L.F. and SOOD D.K., Rad. Eff. 63 (1982) 105 .

/14/ DONA' DALLE ROSE L.F., this conference.

/15/ SMITHELLS C.J., "Metals Reference Book", p. 206, Butterworths, London (1975).

16/ JAIN A.K., KULKARNI V.N. and SOOD D.K., Nucl. Instrum. Methods 191 (1981) 151.

/17/ P. 939 in Ref. 15. 